\title{
BATCH SIZE OPTIMIZATION OF MULTI-STAGE FLOW LINES IN TERMS OF MASS CUSTOMIZATION
}

\author{
Modrak, V. \& Soltysova, Z. \\ Technical University of Kosice, Faculty of Manufacturing Technologies, Bayerova 1, 08001 Presov, \\ Slovakia \\ E-Mail: vladimir.modrak@tuke.sk, zuzana.soltysova@tuke.sk
}

\begin{abstract}
As known, new paradigmatic manufacturing strategies, such as mass customization, bring many new challenges. One of them is batch size optimization since it allows lead time and cost reduction, what are the main preconditions of successful implementation of this strategy. This paper offers an effective solution to optimize batch sizes in order to minimize product lead times and maximize system throughput. Proposed solution considers the classic problem of sequencing a set of jobs that arrive in different combinations over time in a make-to-order (MTO) flow-shop type production. This paper is divided into the four main sections, starting with related work and proposed methodology. Then, approach to batch size strategy optimization is explained. The proposed method is presented through the case study, in the next main section. Finally, discussion and concluding remarks are provided.

(Received in February 2020, accepted in May 2020. This paper was with the authors 1 month for 1 revision.)
\end{abstract}

Key Words: Mass Customization, Scheduling, Flow Shop, Batch Sizing, Due Date, Makespan

\section{INTRODUCTION}

Mass customization as a growing phenomenon in business practice brings manufacturers not only new business opportunities but also new difficulties in its implementation or adaptation [1-3]. One of the ways to obtain expected cost effectiveness is through the reduction of work in process inventories and effective machine utilization by improving production procedures for planning and subsequent control. However, existing approaches for balancing assembly lines don't work well enough. It's because of it that mass customization is disruptive in its nature since it combines three production strategies, namely lean manufacturing, synchronous manufacturing and agile manufacturing. Important questions that have been raised in this context are what batch-size strategy is the most efficient for the mass customisation environment (MC) practise, and which type of assembly model optimally suits for MC environment. Basically, Mixed Model Assembly Lines (MiMALs) and Multi-Model Assembly Lines (MuMALs) have been recognized as suitable alternatives for the given purpose. The problem of producing customized products in MiMALs and MuMALs with different demand features within the same planning period can be reduced to producing the minimum part set in repeating cycles to meet the total demand [4]. Such cyclic schedules ensure better station utilization, improved material handling and material flow, shorter manufacturing lead times, reduced planning and control costs, decreased inventory levels, and increased labour efficiency due to standardization [5].

In this paper, we propose an iterative and practical procedure to optimize batch sizes in order to minimize makespan of jobs and maximize system throughput. The novelty of this study lies in the following: (i) a new concept of batch sizing in terms of MC is explored, with the aim of finding an optimal solution (see Section 4); (ii) a novel framework for assigning of jobs under given constraints is proposed (see Section 5). 


\section{RELATED WORK}

Firstly, it is needful to note that mass customization makes assembly line balancing problems more difficult and more important for manufacturers, and therefore the extended line balancing problems are topical. In this context, Battaïa and Dolgui [6] provided a taxonomy of line balancing problems and their solutions, with the aim of identifying possible methods for resolving future line balancing problems. In a large number of real situations, production managers face the dilemma of whether to apply a mixed-model or multi-model assembly line, respectively. A comparison of these two models with the primary objective of reducing total cycle time was provided by Liao [7]. A related work on a novel heuristic method for the MiMAL balancing problem was published by Jin and $\mathrm{Wu}$ [8]. In order to minimize the time and costs, customized products are frequently assembled in batches [9, 10]. In this context, Fisel et al. [11] offered an approach to convert SMALs into MuMALs as a reaction to customers in the automotive sector demanding an increasing amount of variants. As subsequent step after the selection of an assembly line model, a determination of batch size strategy should be made. This problem has been tackled, e.g., by Hachicha et al. [12], who proposed a method based on discrete event simulation models to determine optimal lot sizes in supply chains that operate in MTO environments. A comprehensive review on recent progress in the lot-sizing problem was presented by Karimi et al. [13]. Jans and Degraeve [14] offered an overview of developments in the field of modelling deterministic single-level dynamic lot-sizing problems. Glock [15] proposed methods for reducing lead time by incorporating a lot-size variable, assuming that the lead time consists of production, setup and transportation times. Related discrete lot-sizing and scheduling problems in ten unrelated parallel workstations were studied by Silva and Magalhaes [16]. A final step of the proposed method is the assignment of production orders to available assembly lines. A relevant and comprehensive literature review for multi-operation scheduling problems with consideration of due dates, earliness and tardiness was offered by Lauff and Werner [17]. Moreover, there are several related studies, e.g., [18-20] focusing directly or indirectly on sequencing and scheduling problems for solving permutation flow-shop problems. Chen et al. [21] proposed a methodical tool based on mathematical programming to solve scheduling problems by the minimization of the total weighted completion time. According to $\mathrm{Xu}$ et al. [22], intelligent algorithms can be effectively used to find the optimal solution for a large-scale problem. In fact, the solutions to scheduling problems often depend on how successfully newly obtained data from a production control layer are synchronized into a Manufacturing Execution System or an Enterprise Resource Planning system [23, 24]. Finally, it is important to point out that according to Yao and Liu [25], the supply chain scheduling optimization in MC belongs to a forefront research field, because it provides various techniques that are of great potential for addressing challenges in mass customization.

\section{PROPOSED METHODOLOGY}

We consider the permutation flow-shop scheduling problem (PFSP), in which the processing order of the jobs in relation to the resources is the same for each subsequent step of processing. Moreover, the following assumptions and constraints will be taken into account:

1) Setup times are included in the processing times, or are even ignored,

2) Each machine can process, at most, one job at a time,

3) Each job can be processed, at most, on one machine at a time,

4) The processing time at each machine for each job is known,

5) The quantity of each job depends on random orders, 
6) Daily production orders (DPOs) for customized jobs are processed on the next day,

7) Identical jobs of DPOs create production batches $(P B)$,

8) The sequence of jobs on all machines is determined based on the makespan criterion,

9) The operational due date is predetermined for all jobs and for a given period.

The overall methodological steps of the proposed approach are depicted in Fig. 1, where decisive chronological actions are briefly outlined.

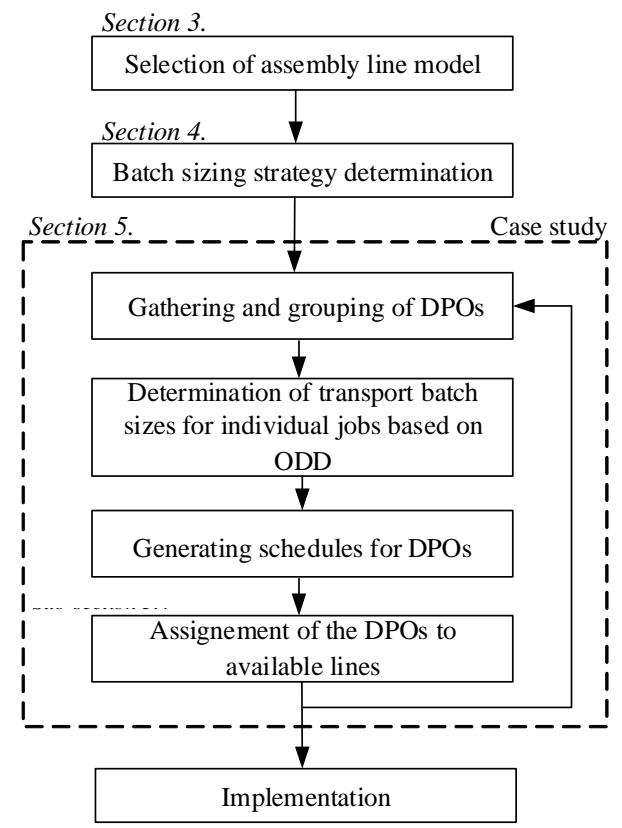

\begin{tabular}{|l|l|}
\hline Abbreviation & Full form \\
\hline A & Assumption \\
\hline Alt. & Alternative \\
\hline Cmax & Makespan \\
\hline D & Day \\
\hline DPOs & Daily Production Orders \\
\hline J & Job \\
\hline L & Number of transportbatches \\
\hline M & workstation \\
\hline MC & Mass customization \\
\hline MiMALs & Mixed Model Assembly Lines \\
\hline MTO & Make-to-order \\
\hline MuMALs & Multi Model Assembly Lines \\
\hline ODD & Operational Due Date \\
\hline OPF & One-piece flow \\
\hline PB & Production batch \\
\hline PFSP & Permutation flow-shop scheduling problem \\
\hline PLB & Production Line Balancing rate \\
\hline RS & Remaining Slack \\
\hline S & Scenario \\
\hline SCH & Schedule of DPO of a given day \\
\hline SMAL & Single Model Assembly Lines \\
\hline TB & Transport batch \\
\hline
\end{tabular}

Figure 1: Stages of the suggested approach (left); list of abbreviations along with their full forms (right).

Proposed procedure starts with a selection of assembly line model, which would be the most suitable for mass customization environment. Here it is explained, why a multi-model assembly line has been selected for the given problem. As known, there are several assembly line models, which are frequently divided into two basic types: (i) SMAL, in which only one model is assembled, and (ii) MuMAL, which is used to produce more than one model or job. A special case of MuMAL is MiMAL, in which products are processed in line with the Onepiece flow concept. In other words, the mixed-model and multi-model line balancing problems differ in terms of the lot sizes and objectives [26]. The purpose of the MuMAL is to minimize the costs of production, such as setup costs, and therefore MuMAL model is considered to be more suitable for MC than MiMAL, where only the idle time of the station is taken into account in most cases [27].

\section{BATCH SIZE STRATEGY DETERMINATION}

Prior to a specification and exploration of the possible batch-size strategies to select the most appropriate transport batch-size method, the working assumptions will be formulated.

\subsection{Working assumptions}

In our research construct, the following three assumptions (A) were considered:

A\#1: Mass customized products are usually more expensive than standard products, therefore the role of mass customizers is to adjust their prices according to the market demands [28].

A\#2: Manufacturing lead times of mass customized products are longer than in the case of the manufacturing of standard products, and accordingly there is a need to reduce delivery 
times simultaneously. This statement is supported by a research conducted by Duray et al. [29]. However, there is lack of specific procedures for the designing or redesigning of production systems dedicated to mass customization [30]. Therefore, the next assumption will be used to justify our approach to solving the scheduling problem presented in this paper.

A\#3: One of possible manufacturing strategies for $\mathrm{MC}$ can be based on a combination of agile manufacturing and lean manufacturing [31].

The agile manufacturing approach is considered here to be the inevitable successor to batch production, and the ideal form of lean manufacturing is the One-Piece Flow (OPF) concept. In the case of the OPF, the makespan (Cmax) is the lowest and the number of changeovers is the highest. On the other hand, job shop manufacturing effects longest makespans and minimizes the number of changeovers. Then, a trade-off between OPF and agile manufacturing can be used as a base for finding a suitable batch-size strategy in terms of MC. Such a strategy can be based, in principle, on the two different scenarios: Scenario 1 (S1) supposes uniform number of transport batches $(L)$ and Scenario 2 (S2) considers uniform transport batch $(T B)$ sizes for all jobs. When distinction between two types of batches, production batch $(P B)$ and transport batch (also referred to as transfer batch) is considered, then the mutual relation between $T B$ and $L$ for the given job $J_{i}$, where $i=1, \ldots, n$ can be described as:

$$
T B_{i}=P B_{i} / L_{i}
$$

Here, production batch of $i^{\text {th }}$ job $\left(P B_{i}\right)$ represents the quantity of items produced on a machine without interruption, whereas a transport batch is the size of products moved after production on one machine to another operation or machine. Subsequently, the question is: 'Which of the two above-mentioned scenarios is more suitable for scheduling in terms of mass customized manufacturing, and why?'. The answer to this question will be explored through computational experiments described in the next subsection.

\subsection{Exploration of the possible batch-size strategy}

In order to decide which of the two concurrent approaches (S1 and S2) is better suited for a given mass customization environment, the pros and cons method for two-option problemsolving will be used. For this assessment purpose the four criteria will be employed:

i. Makespan $\rightarrow$ min,

ii. Number of changeovers $\rightarrow \min$,

iii. Idle time $\rightarrow$ min,

iv. Remaining slack $\left(R S_{i}\right) \rightarrow$ max.

The first three characteristics, i.e. makespan, number of changeovers, and idle times, will be enumerated through online open software [32].

The remaining slack indicator will be calculated using the following formula [33]:

$$
R S_{i}=O D D_{i}-p_{i}-t, \quad \text { [days] }
$$

where $R S_{i}$ is the remaining slack of $i^{\text {th }}$ job, $O D D_{i}$ is the operational due date of $i^{\text {th }}$ job, $p_{i}$ is the processing time of $i^{\text {th }}$ job, and $t$ is the time of the schedule, while $t=0$.

Further, eight PFSPs with three machines $M_{j}$, where $j=1, \ldots, m$ and three jobs will be used to mutually compare all the two scenarios. The quantities of all three jobs, i.e., $P B_{1}=18$, $P B_{2}=12$ and $P B_{3}=6$ will be here considered to be identical for the eight problems and the two scenarios. Moreover, the same sequence of jobs $\left(\mathrm{J}_{3}-\mathrm{J}_{2}-\mathrm{J}_{1}\right)$ will be used for each PFSP. Operation times of $i^{\text {th }}$ job on $j^{\text {th }}$ machine $-t_{i j}$, will vary for each PFSP. Then, 16 computational experiments can be carried out separately for each PFSP by using input data, which are available in Table I. 
Table I: Input data including processing times for all experiments.

\begin{tabular}{|c|c|c|c|c|c|c|c|c|c|c|c|c|c|c|c|c|}
\hline \multirow{2}{*}{$\begin{array}{l}\text { No. of } \\
\text { PFSP }\end{array}$} & \multirow{2}{*}{$\begin{array}{c}\text { Scena- } \\
\text { rios }\end{array}$} & \multicolumn{9}{|c|}{ Processing times (hours) } & \multicolumn{3}{|c|}{$L_{i}$} & \multicolumn{3}{|c|}{$T B_{i}$} \\
\hline & & $t_{11}$ & $t_{12}$ & $t_{13}$ & $t_{21}$ & $t_{22}$ & $t_{23}$ & $t_{31}$ & $t_{32}$ & $t_{33}$ & $L_{1}$ & $L_{2}$ & $L_{3}$ & $T B_{1}$ & $T B_{2}$ & $T B_{3}$ \\
\hline \multirow{2}{*}{1} & S1 & 2 & 2 & 2 & 2 & 2 & 2 & 2 & 2 & 2 & 2 & 2 & 2 & 9 & 6 & 3 \\
\hline & S2 & 2 & 2 & 2 & 2 & 2 & 2 & 2 & 2 & 2 & 9 & 6 & 3 & 2 & 2 & 2 \\
\hline \multirow{2}{*}{2} & S1 & 3 & 3 & 3 & 3 & 3 & 3 & 3 & 3 & 3 & 3 & 3 & 3 & 6 & 4 & 2 \\
\hline & S2 & 3 & 3 & 3 & 3 & 3 & 3 & 3 & 3 & 3 & 6 & 4 & 2 & 3 & 3 & 3 \\
\hline \multirow{2}{*}{3} & S1 & 3 & 5 & 3 & 2 & 3 & 4 & 1 & 2 & 4 & 2 & 2 & 2 & 9 & 6 & 3 \\
\hline & S2 & 3 & 5 & 3 & 2 & 3 & 4 & 1 & 2 & 4 & 9 & 6 & 3 & 2 & 2 & 2 \\
\hline \multirow{2}{*}{4} & S1 & 15 & 12 & 10 & 9 & 16 & 8 & 3 & 8 & 7 & 2 & 2 & 2 & 9 & 6 & 3 \\
\hline & S2 & 15 & 12 & 10 & 9 & 16 & 8 & 3 & 8 & 7 & 9 & 6 & 3 & 2 & 2 & 2 \\
\hline \multirow{2}{*}{5} & S1 & 38 & 39 & 25 & 35 & 34 & 28 & 20 & 32 & 25 & 2 & 2 & 2 & 9 & 6 & 3 \\
\hline & S2 & 38 & 39 & 25 & 35 & 34 & 28 & 20 & 32 & 25 & 9 & 6 & 3 & 2 & 2 & 2 \\
\hline \multirow{2}{*}{6} & S1 & 4 & 5 & 7 & 3 & 4 & 7 & 2 & 3 & 6 & 3 & 3 & 3 & 6 & 4 & 2 \\
\hline & S2 & 4 & 5 & 7 & 3 & 4 & 7 & 2 & 3 & 6 & 6 & 4 & 2 & 3 & 3 & 3 \\
\hline \multirow{2}{*}{7} & S1 & 12 & 10 & 8 & 11 & 5 & 7 & 8 & 6 & 6 & 3 & 3 & 3 & 6 & 4 & 2 \\
\hline & S2 & 12 & 10 & 8 & 11 & 5 & 7 & 8 & 6 & 6 & 6 & 4 & 2 & 3 & 3 & 3 \\
\hline \multirow[b]{2}{*}{8} & S1 & 33 & 25 & 20 & 19 & 17 & 20 & 12 & 15 & 18 & 3 & 3 & 3 & 6 & 4 & 2 \\
\hline & S2 & 33 & 25 & 20 & 19 & 17 & 20 & 12 & 15 & 18 & 6 & 4 & 2 & 3 & 3 & 3 \\
\hline
\end{tabular}

Related Gantt charts for concurrent scenarios (S1 and S2) are depicted in Fig. 2.
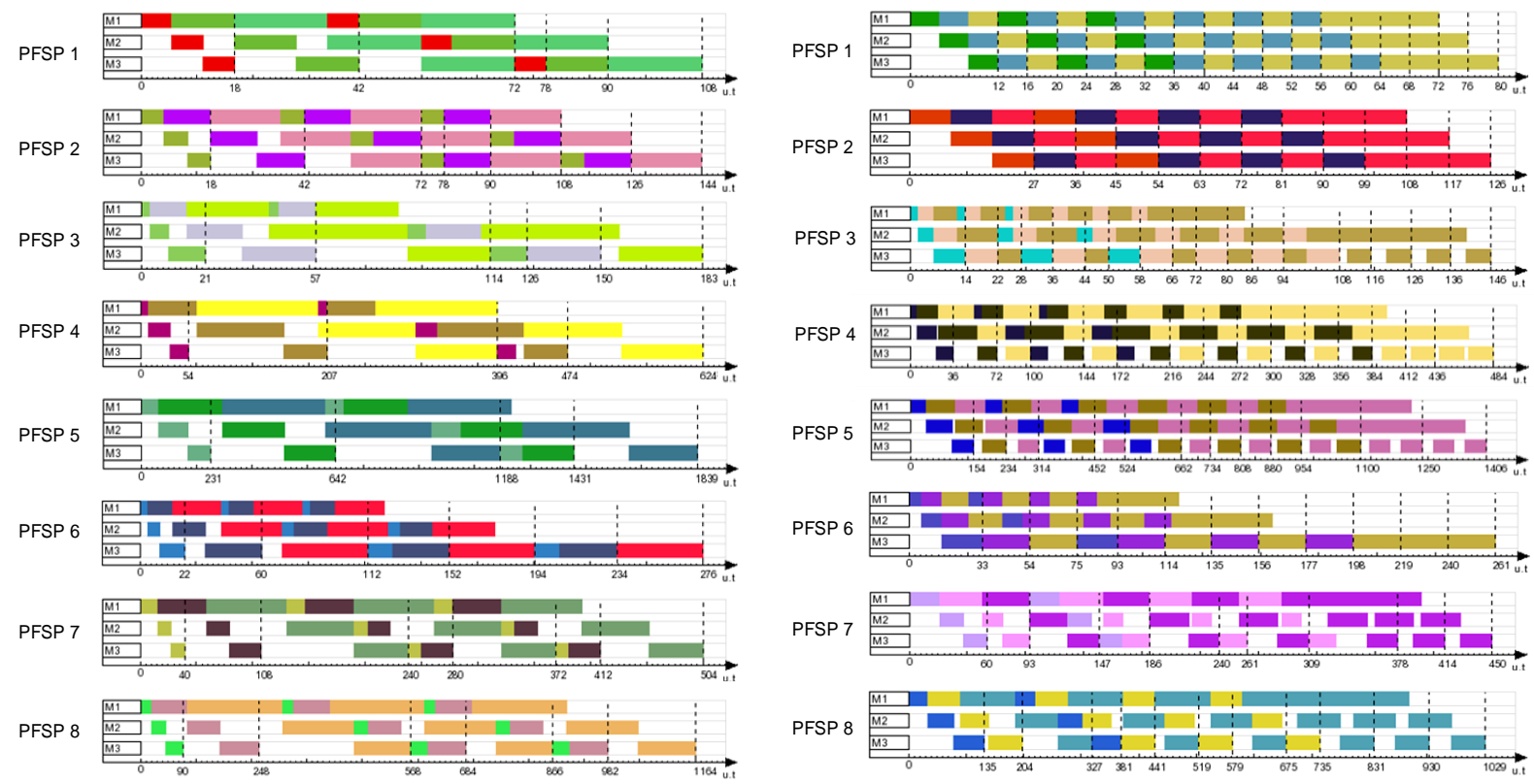

Figure 2: Gantt charts for all experiments of S1 (left); Gantt charts for all experiments of S2 (right).

All Gantt charts were generated by using the open source software, by which makespans, number of changeovers, idle times, and processing times of given jobs $\left(p_{i}\right)$ were simultaneously enumerated. To obtain average remaining slack values for each of 16 experiments, firstly $R S i$ values for individual jobs need to be calculated by Eq. (2). For this purpose, $O D D$ s values will be determined for each PFSP separately as the means of Cmax values of the two scenarios. For example, for FPSP $1, \operatorname{Cmax}_{\mathrm{S} 1}=4,5$ days and $\operatorname{Cmax}_{\mathrm{S} 2}=3,33$ days (see Table II). Then $O D D$ equals 3,92 days, and it is rounded to the nearest higher integer value - four days. Input data for average RS values calculation for the eight problems and the two scenarios are shown in Table II. 
Table II: Average RS values for the eight PFS problems.

\begin{tabular}{|c|c|c|c|c|c|c|}
\hline $\begin{array}{l}\text { No. of } \\
\text { PFSP }\end{array}$ & $\begin{array}{c}\text { Cmax of } \\
\text { scenarios (days) }\end{array}$ & $\begin{array}{r}\boldsymbol{O D D} \\
\text { (days) }\end{array}$ & $\begin{array}{c}p_{i} \text { of } \mathbf{S 1} \\
\text { (days) }\end{array}$ & $\begin{array}{c}\boldsymbol{p}_{\boldsymbol{i}} \text { of } \mathbf{S 2} \\
\text { (days) }\end{array}$ & $R S$ of $S 1$ (days) & $R S$ of $S 2$ (days) \\
\hline 1 & $\begin{array}{c}C \max _{\mathrm{S} 1}=4,5 \\
C \max _{\mathrm{S} 2}=3,33\end{array}$ & 4 & $\begin{array}{c}p_{1}=4,5 \\
p_{2}=3,75 \\
p_{3}=3,25\end{array}$ & $\begin{array}{l}p_{1}=3,33 \\
p_{2}=2,67 \\
p_{3}=1,50\end{array}$ & $\begin{array}{l}R S_{1}=-0,5 \\
R S_{2}=0,25 \\
R S_{3}=0,75 \\
\boldsymbol{\Phi R S}=\mathbf{0 . 1 7}\end{array}$ & $\begin{array}{l}R S_{1}=0,67 \\
R S_{2}=1,33 \\
R S_{3}=2,50 \\
\boldsymbol{\Phi R S}=\mathbf{1 . 5}\end{array}$ \\
\hline 2 & $\begin{array}{c}\operatorname{Cmax}_{\mathrm{S} 1}=6 \\
\operatorname{Cmax}_{\mathrm{S} 2}=5,25\end{array}$ & 6 & $\begin{array}{c}p_{1}=6 \\
p_{2}=5,25 \\
p_{3}=4,75\end{array}$ & $\begin{array}{l}p_{1}=5,25 \\
p_{2}=4,13 \\
p_{3}=2,25\end{array}$ & $\begin{array}{c}R S_{1}=0 \\
R S_{2}=0,75 \\
R S_{3}=1,25 \\
\boldsymbol{\Phi R S}=\mathbf{0 , 6 7}\end{array}$ & $\begin{array}{c}R S_{1}=0,75 \\
R S_{2}=1,87 \\
R S_{3}=3,75 \\
\boldsymbol{\Phi R S}=\mathbf{2 , 1 2}\end{array}$ \\
\hline 3 & $\begin{array}{l}\operatorname{Cmax}_{\mathrm{S} 1}=7,63 \\
\operatorname{Cmax}_{\mathrm{S} 2}=6,08\end{array}$ & 7 & $\begin{array}{l}p_{1}=7,63 \\
p_{2}=6,25 \\
p_{3}=5,25\end{array}$ & $\begin{array}{c}p_{1}=6,08 \\
p_{2}=4,5 \\
p_{3}=2,42\end{array}$ & $\begin{array}{c}R S_{1}=-0,63 \\
R S_{2}=0,75 \\
R S_{3}=1,75 \\
\boldsymbol{\Phi R S}=\mathbf{0 , 6 2} \\
\end{array}$ & $\begin{array}{c}R S_{1}=0,92 \\
R S_{2}=2,5 \\
R S_{3}=4,58 \\
\boldsymbol{\Phi} \boldsymbol{R} \boldsymbol{S}=\mathbf{2 , 6 7}\end{array}$ \\
\hline 4 & $\begin{array}{c}\operatorname{Cmax}_{\mathrm{S} 1}=26 \\
\operatorname{Cmax}_{\mathrm{S} 2}=20,17\end{array}$ & 24 & $\begin{array}{c}p_{1}=26 \\
p_{2}=19,75 \\
p_{3}=17,38\end{array}$ & $\begin{array}{c}p_{1}=20,17 \\
p_{2}=16 \\
p_{3}=7,75\end{array}$ & $\begin{array}{c}R S_{1}=-2 \\
R S_{2}=4,25 \\
R S_{3}=6,62 \\
\boldsymbol{\Phi} \boldsymbol{R} \boldsymbol{S}=\mathbf{2 , 9 6}\end{array}$ & $\begin{array}{c}R S_{1}=3,83 \\
R S_{2}=8 \\
R S_{3}=16,25 \\
\boldsymbol{\Phi} \boldsymbol{R} \boldsymbol{S}=\mathbf{9 , 3 6}\end{array}$ \\
\hline 5 & $\begin{array}{l}\operatorname{Cmax}_{\mathrm{S} 1}=76,63 \\
\operatorname{Cmax}_{\mathrm{S} 2}=58,58\end{array}$ & 68 & $\begin{array}{l}p_{1}=76,63 \\
p_{2}=59,63 \\
p_{3}=52,63\end{array}$ & $\begin{aligned} p_{1} & =58,58 \\
p_{2} & =45,83 \\
p_{3} & =24,5\end{aligned}$ & $\begin{array}{c}R S_{1}=-8,63 \\
R S_{2}=8,37 \\
R S_{3}=15,37 \\
\boldsymbol{\Phi} \boldsymbol{R}=\mathbf{5 , 0 4}\end{array}$ & $\begin{array}{c}R S_{1}=9,42 \\
R S_{2}=22,17 \\
R S_{3}=43,5 \\
\boldsymbol{\Phi} \boldsymbol{R} \boldsymbol{S}=\mathbf{2 5 , 0 3}\end{array}$ \\
\hline 6 & $\begin{array}{c}\operatorname{Cmax}_{\mathrm{S} 1}=11,5 \\
\operatorname{Cmax}_{\mathrm{S} 2}=10,88\end{array}$ & 12 & $\begin{array}{l}p_{1}=11,5 \\
p_{2}=9,75 \\
p_{3}=8,58\end{array}$ & $\begin{array}{c}p_{1}=10,88 \\
p_{2}=8,25 \\
p_{3}=3,88\end{array}$ & $\begin{array}{c}R S_{1}=0,5 \\
R S_{2}=2,25 \\
R S_{3}=3,42 \\
\boldsymbol{\Phi} \boldsymbol{R} \boldsymbol{S}=\mathbf{2 , 0 6}\end{array}$ & $\begin{array}{c}R S_{1}=1,12 \\
R S_{2}=3,75 \\
R S_{3}=8,12 \\
\boldsymbol{\Phi} \boldsymbol{R} \boldsymbol{S}=\mathbf{4 , 3 3}\end{array}$ \\
\hline 7 & $\begin{array}{c}\operatorname{Cmax}_{\mathrm{S} 1}=21 \\
\operatorname{Cmax}_{\mathrm{S} 2}=18,75\end{array}$ & 20 & $\begin{array}{c}p_{1}=21 \\
p_{2}=17,17 \\
p_{3}=16\end{array}$ & $\begin{array}{c}p_{1}=18,75 \\
p_{2}=13,75 \\
p_{3}=6,88\end{array}$ & $\begin{array}{c}R S_{1}=-1 \\
R S_{2}=2,83 \\
R S_{3}=4 \\
\boldsymbol{\Phi} \boldsymbol{R} \boldsymbol{S}=\mathbf{1 , 9 4}\end{array}$ & $\begin{array}{c}R S_{1}=1,25 \\
R S_{2}=6,25 \\
R S_{3}=13,12 \\
\boldsymbol{\Phi R S}=\mathbf{6 , 8 7}\end{array}$ \\
\hline 8 & $\begin{array}{c}\operatorname{Cmax}_{\mathrm{S} 1}=48,5 \\
\operatorname{Cmax}_{\mathrm{S} 2}=42,88\end{array}$ & 46 & $\begin{array}{c}p_{1}=48,5 \\
p_{2}=40,92 \\
p_{3}=37,58\end{array}$ & $\begin{array}{l}p_{1}=42,88 \\
p_{2}=30,63 \\
p_{3}=15,88\end{array}$ & $\begin{array}{c}R S_{1}=-2,5 \\
R S_{2}=5,08 \\
R S_{3}=8,42 \\
\boldsymbol{\Phi} \boldsymbol{R} \boldsymbol{S}=\mathbf{3 , 6 7}\end{array}$ & $\begin{array}{c}R S_{1}=3,12 \\
R S_{2}=15,37 \\
R S_{3}=30,12 \\
\boldsymbol{\Phi} \boldsymbol{R} \boldsymbol{S}=\mathbf{1 6 , 2}\end{array}$ \\
\hline
\end{tabular}
III.

Finally, the obtained values from all computational experiments are summarized in Table

Table III: Summarization of obtained values for all computational experiments.

\begin{tabular}{|c|c|c|c|c|c|c|c|c|}
\hline \multirow{2}{*}{$\begin{array}{c}\text { No. of } \\
\text { PFSP }\end{array}$} & \multicolumn{2}{|c|}{$\boldsymbol{C m a x}$ (days) } & \multicolumn{2}{c|}{$\boldsymbol{\Phi R S}$ (days) } & \multicolumn{2}{c|}{ Idle time (days) } & \multicolumn{2}{c|}{ No. of changeovers } \\
\cline { 2 - 8 } & $\mathrm{S} 1$ & $\mathrm{~S} 2$ & $\mathrm{~S} 1$ & $\mathrm{~S} 2$ & $\mathrm{~S} 1$ & $\mathrm{~S} 2$ & S1 & S2 \\
\hline 1 & 4,50 & 3,33 & 0,17 & 1,50 & 1,5 & 0 & 15 & 42 \\
\hline 2 & 6,00 & 5,25 & 0,67 & 2,12 & 1,5 & 0 & 24 & 27 \\
\hline 3 & 7,63 & 6,08 & 0,62 & 2,67 & 2,63 & 0,58 & 15 & 42 \\
\hline 4 & 26 & 20,17 & 2,96 & 9,36 & 14,25 & 6,08 & 15 & 42 \\
\hline 5 & 76,63 & 58,58 & 5,04 & 25,03 & 41,63 & 15,83 & 15 & 42 \\
\hline 6 & 11,50 & 10,88 & 2,06 & 4,33 & 1,42 & 0 & 24 & 27 \\
\hline 7 & 21 & 18,75 & 1,94 & 6,87 & 15,67 & 11,25 & 24 & 27 \\
\hline 8 & 48,5 & 42,88 & 3,67 & 16,2 & 28,25 & 17,88 & 24 & 27 \\
\hline
\end{tabular}

In comparing S1 and S2, which is shown in Table IV, the scenario with the more suitable value is assigned the symbol "+" and the scenario with the less suitable value is assigned the symbol "-". From Table IV, it is clear that S2 with a uniform transport batch sizes brings better results than $\mathrm{S} 1$ for all eight theoretical PFSPs.

Table IV: Comparison of scenario 1 against scenario 2.

\begin{tabular}{|c|c|c|c|c|c|c|c|c|c|c|c|c|c|c|c|c|}
\hline \multirow{2}{*}{$\begin{array}{c}\text { Criterion / No. } \\
\text { of PFSP }\end{array}$} & \multicolumn{8}{|c|}{ Scenario 1} & \multicolumn{8}{|c|}{ Scenario 2} \\
\hline & 1 & 2 & 3 & 4 & 5 & 6 & 7 & 8 & 1 & 2 & 3 & 4 & 5 & 6 & 7 & 8 \\
\hline Cmax & - & - & - & - & - & - & - & - & + & + & + & + & + & + & + & + \\
\hline$R S$ & - & - & - & - & - & - & - & - & + & + & + & + & + & + & + & + \\
\hline Idle time & - & - & - & - & - & - & - & - & + & + & + & + & + & + & + & + \\
\hline No. of changeovers & + & + & + & + & + & + & + & + & - & - & - & - & - & - & - & - \\
\hline
\end{tabular}

Based on the comparison, it is not possible to unambiguous state that one of the two scenarios is more suitable than the other. But this finding can be effectively applied in practice. For time-based optimization problem - S2 suits better than S1, and for cost-based optimization problem - it is vice versa. As it was specified in abovementioned assumptions 
(see A\#1 and A\#2 in sub-section 4.1), both optimization objectives are pertinent in terms of mass customization. Taking into account theoretical consideration that time-based optimization is more significant than cost-based optimization, and then there are usually several possible solutions under scenario S2. In order to show how in such case an optimal schedule can be found, a realistic case study example is offered in the next section.

\section{CASE STUDY}

Let us consider the case study of a manufacturing system containing 8 machines or workstations (M), where three jobs, marked as $\mathbf{J}_{1}, \mathbf{J}_{2}$ and $\mathbf{J}_{3}$, are produced. For the scheduling problem $m \times n$ with processing times for each job $(n)$ on each workstation $(m)$, the following times were adopted from Zhang et al. [34]: $t_{11}=860, t_{12}=670, t_{13}=860, t_{21}=756, t_{22}=1018$, $t_{23}=649, t_{31}=653, t_{32}=870, t_{33}=811, t_{41}=750, t_{42}=831, t_{43}=770, t_{51}=879, t_{52}=510$, $t_{53}=979, t_{61}=457, t_{62}=986, t_{63}=487, t_{71}=534, t_{72}=1148, t_{73}=534, t_{81}=876, t_{82}=820$, $t_{83}=610$ (in seconds).

It will be assumed that the job sequence will be based on the Cmax criterion as follows, $\mathbf{J}_{3}-\mathbf{J}_{2}-\mathbf{J}_{1}$, the $O D D$ s for all three jobs are predetermined as 3 days, and production will take place in three shifts, for 24 hours.

\subsection{Gathering and grouping of daily orders}

Since the first step of the proposed method is grouping equal individual orders (jobs) per short time periods (into days in given case), let us consider that the numbers of grouped orders of the initial day are $P B_{1}=102 ; P B_{2}=84$ and $P B_{3}=52$.

The number of ordered daily quantities needs to be restructured, because the quantities are not in the form of rounding to the nearest 10. For this purpose, the ordered quantities of the first job $\left(P B_{1}\right)$ will be divided into the two sub-batches (A and $\left.\mathrm{B}\right) P B_{1 \mathrm{~A}}=100$ and $P B_{1 \mathrm{~B}}=2$, where $T B_{1 \mathrm{~B}}=2$ and $L_{1 \mathrm{~B}}=1 ; P B_{2}$ is divided into $P B_{2 \mathrm{~A}}=80$ and $P B_{2 \mathrm{~B}}=4$, where $T B_{2 \mathrm{~B}}=4$ and $L_{2 \mathrm{~B}}=1$; the quantity of $P B_{3}$ is separated into $P B_{3 \mathrm{~A}}=50$ and $P B_{3 \mathrm{~B}}=2$, where $T B_{3 \mathrm{~B}}=2$ and $L_{3 \mathrm{~B}}=1$. The same procedure will be repeated for the subsequent daily orders (from D2 to D18). The values of daily orders before and after modification are depicted in Table V.

Table V: Summarization of all orders before modification and summarization of all daily orders with restructured quantities.

\begin{tabular}{|c|c|c|c|c|c|c|c|c|c|c|c|c|c|c|c|c|c|c|c|}
\hline \multirow{2}{*}{ DPOs } & \multirow{2}{*}{$P B_{i}$} & \multicolumn{18}{|c|}{ Ordered cumulative quantities of the day $(D)$} \\
\hline & & D1 & D2 & D3 & $D 4$ & D5 & D6 & D7 & D8 & D9 & D10 & $D 11$ & D12 & D13 & D14 & D15 & D16 & D17 & D18 \\
\hline \multirow{3}{*}{ 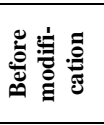 } & $P B_{1}$ & 102 & 83 & 102 & 124 & 102 & 201 & 83 & 102 & 124 & 163 & 102 & 83 & 124 & 102 & 83 & 201 & 124 & 102 \\
\hline & $P B_{2}$ & 84 & 42 & 84 & 51 & 84 & 106 & 42 & 84 & 51 & 105 & 84 & 42 & 51 & 84 & 42 & 106 & 51 & 84 \\
\hline & $P B_{3}$ & 52 & 33 & 52 & 36 & 52 & 54 & 33 & 52 & 36 & 52 & 52 & 33 & 36 & 52 & 33 & 54 & 36 & 52 \\
\hline \multirow{6}{*}{ 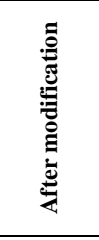 } & $P B_{1 \mathrm{~A}}$ & 100 & 80 & 100 & 120 & 100 & 200 & 80 & 100 & 120 & 160 & 100 & 80 & 120 & 100 & 80 & 200 & 120 & 100 \\
\hline & $P B_{1 \mathrm{~B}}$ & 2 & 3 & 2 & 4 & 2 & 1 & 3 & 2 & 4 & 3 & 2 & 3 & 4 & 2 & 3 & 1 & 4 & 2 \\
\hline & $P B_{2 \mathrm{~A}}$ & 80 & 40 & 80 & 50 & 80 & 100 & 40 & 80 & 50 & 100 & 80 & 40 & 50 & 80 & 40 & 100 & 50 & 80 \\
\hline & $P B_{2 \mathrm{~B}}$ & 4 & 2 & 4 & 1 & 4 & 6 & 2 & 4 & 1 & 5 & 4 & 2 & 1 & 4 & 2 & 6 & 1 & 4 \\
\hline & $P B_{3 \mathrm{~A}}$ & 50 & 30 & 50 & 30 & 50 & 50 & 30 & 50 & 30 & 50 & 50 & 30 & 30 & 50 & 30 & 50 & 30 & 50 \\
\hline & $P B_{3 \mathrm{~B}}$ & 2 & 3 & 2 & 6 & 2 & 4 & 3 & 2 & 6 & 2 & 2 & 3 & 6 & 2 & 3 & 4 & 6 & 2 \\
\hline
\end{tabular}

\subsection{Determination of transport batch sizes}

During this step, the optimal $T B_{i}$ values based on the predetermined operational due date (ODD) will be determined. The proposed procedure for finding the optimal $T B$ sizes is as follows:

i. Take the reordered quantities of $P B_{1 \mathrm{~A}}, P B_{2 \mathrm{~A}}, P B_{3 \mathrm{~A}}, P B_{1 \mathrm{~B}}, P B_{2 \mathrm{~B}}$ and $P B_{3 \mathrm{~B}}$. 
ii. Identify the possible uniform $T B$ size of sub-batches $P B_{1 \mathrm{~A}}, P B_{2 \mathrm{~A}}, P B_{3 \mathrm{~A}}$ by finding the common separators, which are 1,2, 5 and 10. The number of common separators determines the possible uniform $T B$ sizes, altogether 4 alternatives.

iii. Calculate $L_{i}$ using Eq. (1) and Cmax values for these four alternatives for orders of the first day (see Table VI).

iv. Choose the optimal alternative with the closest $C \max$ not extending the $O D D$ value. In given case it is alternative 3 .

Table VI: All possible $L_{i}$ and $T B_{i}$ values for D1.

\begin{tabular}{|c|c|c|c|c|c|c|c|c|c|c|c|c|c|c|c|c|c|}
\hline \multirow{2}{*}{$\begin{array}{c}T B \text { size } \\
\text { alt. }\end{array}$} & \multirow{2}{*}{$P B_{1}$} & \multicolumn{2}{|c|}{$P B_{1 \mathrm{~A}}$} & \multicolumn{2}{|c|}{$P B_{1 \mathrm{~B}}$} & \multirow{2}{*}{$P B_{2}$} & \multicolumn{2}{|c|}{$P B_{2 A}$} & \multicolumn{2}{|c|}{$P B_{2 B}$} & \multirow{2}{*}{$P B_{3}$} & \multicolumn{2}{|c|}{$P B_{3 A}$} & \multicolumn{2}{|c|}{$\boldsymbol{P B}_{3 \mathrm{~B}}$} & \multirow{2}{*}{$\begin{array}{l}\text { Cmax } \\
\text { (days) }\end{array}$} & \multirow{2}{*}{$\begin{array}{r}\boldsymbol{O D D} \\
\text { (days) }\end{array}$} \\
\hline & & $L_{1 \mathrm{~A}}$ & $T B_{1 \mathrm{~A}}$ & $L_{1 \mathrm{~B}}$ & $T B_{1 \mathrm{~B}}$ & & $L_{2 \mathrm{~A}}$ & $T B_{2 \mathrm{~A}}$ & $L_{2 \mathrm{~B}}$ & $T B_{2 \mathrm{~B}}$ & & $L_{3 \mathrm{~A}}$ & $T B_{3 \mathrm{~A}}$ & $L_{3 \mathrm{~B}}$ & $T B_{3 \mathrm{~B}}$ & & \\
\hline Alt. 1 & \multirow{4}{*}{102} & 102 & 1 & - & - & \multirow{4}{*}{84} & 84 & 1 & - & - & \multirow{4}{*}{52} & 52 & 1 & - & - & 2,37 & \multirow{4}{*}{3} \\
\hline Alt. 2 & & 51 & 2 & - & - & & 42 & 2 & - & - & & 26 & 2 & - & - & 2,44 & \\
\hline Alt. 3 & & 20 & 5 & 1 & 2 & & 16 & 5 & 1 & 4 & & 10 & 5 & 1 & 2 & 2,66 & \\
\hline Alt. 4 & & 10 & 10 & 1 & 2 & & 8 & 10 & 1 & 4 & & 5 & 10 & 1 & 2 & 3,02 & \\
\hline
\end{tabular}

Above shown procedure will be repeated for subsequent daily orders, in given case for days from D2 to D18 (see Table VII).

Table VII: Optimal TBs for all daily orders.

\begin{tabular}{|c|c|c|c|c|c|c|c|}
\hline \multirow[b]{2}{*}{ DPOs } & \multicolumn{6}{|c|}{ Optimal transport batch sizes } & \multirow{2}{*}{$\begin{array}{l}\text { Final } \\
\text { Cmax } \\
\text { (days) }\end{array}$} \\
\hline & $T B_{1 A}$ & $T B_{1 \mathrm{~B}}$ & $T B_{2 A}$ & $T B_{2 \mathrm{~B}}$ & $T B_{3 A}$ & $T B_{3 \mathrm{~B}}$ & \\
\hline D1, D3, D5, D8, D11, D14 and D18 & 20 & 2 & 16 & 4 & 10 & 2 & 2,66 \\
\hline D2, D7, D12 and D15 & 8 & 3 & 4 & 2 & 3 & 3 & 2,26 \\
\hline D4, D9, D13 and D17 & 12 & 4 & 5 & 1 & 3 & 6 & 2,78 \\
\hline D6 and D16 & 201 & - & 106 & - & 54 & - & 3,62 \\
\hline D10 & 106 & - & 105 & - & 52 & - & 3,21 \\
\hline
\end{tabular}

\subsection{Modelling of aggregate scheduling problems}

Gantt charts obtained in this manner can be used for modelling of detailed aggregate schedules in such a way, that the individual charts will create parts of multi Gantt chart.

Multi Gantt chart starts with abstracted Gantt chart representing schedule of daily production order of the first day (SCH1), which will be allocated to the first available assembly line, as shown in Fig. 3 b.

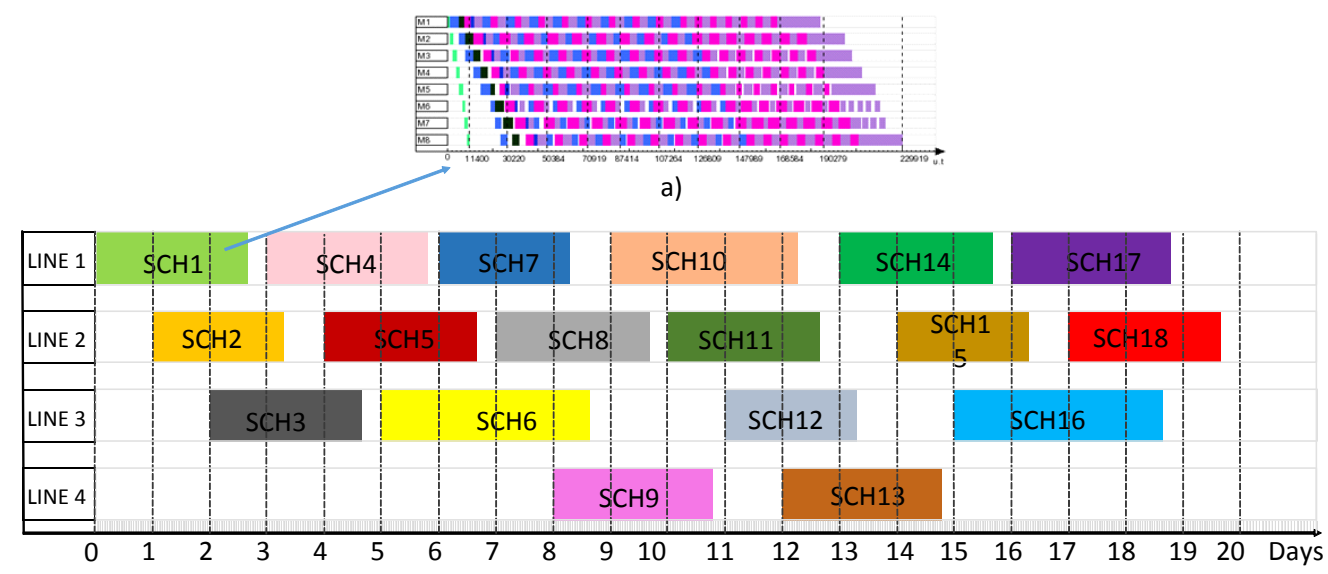

b)

Figure 3: a) Generated Gantt chart for D1; b) First version of aggregate schedule before optimization.

Gantt charts for remaining daily orders can be allocated in the available production lines. In a given case, four production lines are at our disposal, for which table of aggregate 
schedules can be created as shown in Fig. 3 b. This graphical model can be considered to be the first version of the aggregate schedule.

As can be seen, three schedules of individual daily orders, namely of the D6, D16 and D10 are over the $O D D$. By using the software, it is possible to recognize that numbers of delayed jobs for mentioned days are: D6 with 61 delayed parts of $\mathrm{J}_{1}$; D16 with 61 delayed parts of $\mathbf{J}_{1}$; D10 with 21 delayed parts of $\mathbf{J}_{1}$.

Therefore, it is reasonable to split the daily schedules into two parallel sub-schedules because there is room for improvement in the first version of aggregate schedule.

Specifically, the individual schedules for days D6, D16 and D10, where tardiness occurred, will be split into two sub-schedules. For example, SCH6, i.e., schedule for the order of the D6 is divided into two sub-schedules marked as SCH6a, and SCH6b, where PBs of these two sub-schedules are iteratively set up to utilise free spaces in the lines. In our case the following quantities of $P B \mathrm{~s}$ for individual jobs were setup: $P B_{1}=101, P B_{2}=53$ and $P B_{3}=27$ (for SCH6a); $P B_{1}=100, P B_{2}=53$ and $P B_{3}=27$ (for SCH6b); $P B_{1}=82, P B_{2}=53$ and $P B_{3}=26$ (for SCH10a); $P B_{1}=81, P B_{2}=52$ and $P B_{3}=26$ (for SCH10b); $P B_{1}=101, P B_{2}=53$ and $P B_{3}=27$ (for SCH16a); $P B_{1}=100, P B_{2}=53$ and $P B_{3}=27$ (for SCH16b).

The procedure to find the optimal TBs for SCH6a, SCH6b, SCH10a, SCH10b, SCH16a and $\mathrm{SCH} 16 \mathrm{~b}$ will be repeated, where $O D D$ will be decreased by ad hoc decision into two days. The $O D D$ can be in this step modified due to the available time on production lines, namely Line \#3 and Line \#4. If there is not necessary to iteratively change the scheduling parameters, then the obtained values are used for the model of aggregate schedule. Optimized transport batch sizes and Cmax values for days where tardiness occurred are summarily depicted in Table VIII.

Table VIII: Final transport batch sizes and Cmax values for the corrected sub-schedules.

\begin{tabular}{|c|c|c|c|c|c|c|c|}
\hline \multirow{2}{*}{$\begin{array}{c}\text { Sub-schedules } \\
\text { by days }\end{array}$} & \multicolumn{6}{|c|}{ Optimal transport batch sizes } & \multirow{2}{*}{$\begin{array}{c}\text { Final Cmax } \\
\text { (days) }\end{array}$} \\
\hline & $T B_{1 \mathrm{~A}}$ & $T B_{1 \mathrm{~B}}$ & $T B_{2 A}$ & $T B_{2 \mathrm{~B}}$ & $T B_{3 A}$ & $T B_{3 B}$ & \\
\hline SCH6a & 50 & 1 & 26 & 1 & 13 & 1 & 1,92 \\
\hline SCH6b & 50 & - & 26 & 1 & 13 & 1 & 1,91 \\
\hline SCH10a & 16 & 2 & 10 & 3 & 5 & 1 & 1,94 \\
\hline SCH10b & 16 & 1 & 10 & 2 & 5 & 1 & 1,92 \\
\hline SCH16a & 50 & 1 & 26 & 1 & 13 & 1 & 1,92 \\
\hline SCH16b & 50 & - & 26 & 1 & 13 & 1 & 1,91 \\
\hline
\end{tabular}

Finally, the optimized version of aggregate scheduling model is created (see Fig. 4), while the numbers of delayed jobs are eliminated.

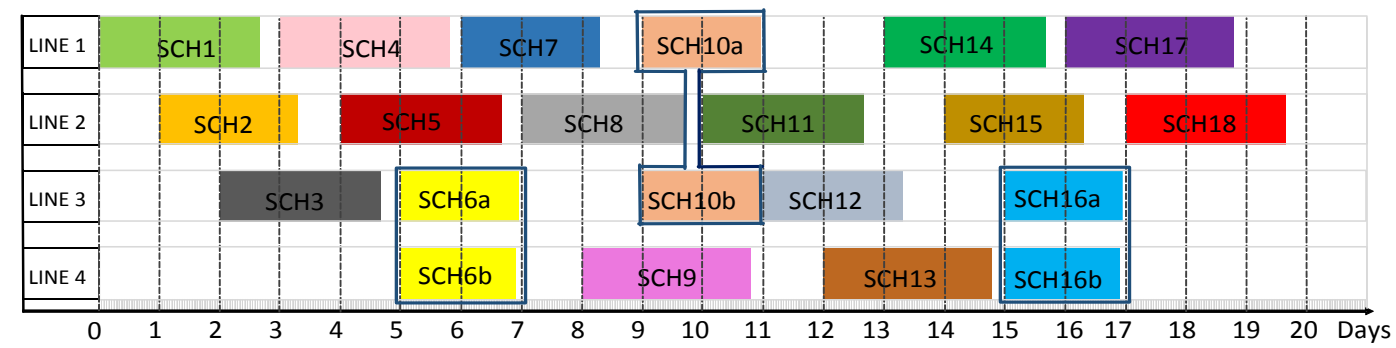

Figure 4: Aggregated scheduling model after optimization.

Due to the fact that dynamic scheduling is often referred to as dynamic load balancing techniques, it is useful to compare the schedule effectiveness between aggregate scheduling models before and after optimization. The formula for Production Line Balancing rate (PLB) will be applied, which is defined as follows [35]:

$$
P L B=\frac{\sum_{i=1}^{n} T[i, j]}{i * \max \left(T_{k}\right)}[\%]
$$


where: $T[i, j]$ is the processing time of the $i^{\text {th }}$ job on $j^{\text {th }}$ workstation, $n$ is the number of jobs, $l$ is the number of lines in the production system, while $l=1,2, \ldots, k$, and $T_{k}$ is the processing time on the $k^{\text {th }}$ production line.

Based on the enumeration of $P L B$ using Eq. (3), we can enumerate $P L B_{1}$ for aggregate scheduling model before optimization and $P L B_{2}$ for aggregate scheduling model after optimization. After optimization, the $P L B_{2}$ equals $64 \%$ against $62.6 \%$ of $P L B_{1}$. This assessment complementarily proves that the aggregated scheduling model after optimization can be considered as more suitable as before optimization.

\section{DISCUSSION AND CONCLUSION}

In order to analyse pros and cons of the proposed method, it is possible to state that its strong point is algorithmic procedure to find optimal batch size when manufacturing conditions and ordered product assortment is more or less similar as in our case study. A potential weakness of this method can be seen in determination of due dates. Especially, when nature of customers' orders is changing dynamically and future orders cannot be easy estimated. This shortcoming can be gradually overcoming only by solving further real scheduling problems from different application areas of mass customization. Another limitation of this approach is missing compact software tool by which would be possible to generate aggregate schedules in shorter time than it is possible through the available software.

The main contribution of this research includes definition and exploration of possible batch-size strategies, by which it was found that S2, i.e., the scenario with uniform sizes of transport batches for all jobs can be effectively used for flexible schedules in mass customized environments. The developed software helps to enumerate makespan values and generate Gantt charts, by which aggregate schedules in form of multi Gantt charts can be modelled. The functionalities of this specialized software allow solving not only small scheduling problems but also medium size instances, which are typical for assembly processes of original equipment manufacturers. Another contribution of this research is novel framework for assigning of jobs under given constraints. Its applicability is exemplified through the realistic case study. The case study results showed that the application of the proposed procedure to optimize lot sizes of customized products can be easily used for generation of aggregate schedules of customized products that must run in a certain sequence in parallel mixed-model assembly lines with fixed capacity. When using this method, it is useful to emphasize the need to specify as small as possible planning periods, e.g., single days. Then, easily identifiable idle times between the beginning and the end of production can be used to increase exploitability of the workstations/machines and human operators. From the practical viewpoint, the proposed method might enable the practitioners to determine optimal batch sizes, which might help minimize lead times of mass customized products.

Future works could be oriented to simulate dynamic mass customization market environment with the aim to generate more realistic structure of orders. Such simulation outputs could be used as inputs for the proposed approach to identify optimal batch sizes for multi-stage assembly flow lines.

\section{ACKNOWLEDGEMENT}

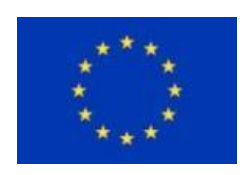

The authors wish to acknowledge the European Union's Horizon 2020 research and innovation program under the Marie Skłodowska-Curie grant agreement No. 734713 and by the KEGA project Nr. 025TUKE-4/2020 granted by the Ministry of Education of the Slovak Republic. 


\section{REFERENCES}

[1] Suzic, N.; Forza, C.; Trentin, A.; Anisic, Z. (2018). Implementation guidelines for mass customization: current characteristics and suggestions for improvement, Production Planning \& Control, Vol. 29, No. 10, 856-871, doi:10.1080/09537287.2018.1485983

[2] Suzic, N.; Sandrin, E.; Suzic, S.; Forza, C.; Trentin, A.; Anisic, Z. (2018). Implementation guidelines for mass customization: a researcher-oriented view, International Journal of Industrial Engineering and Management, Vol. 9, No. 4, 229-243, doi:10.24867/IJIEM-2018-4-229

[3] Suzic, N.; Stevanov, B.; Cosic, I.; Anisic, Z.; Sremcev, N. (2012). Customizing products through application of group technology: a case study of furniture manufacturing, Strojniski vestnik Journal of Mechanical Engineering, Vol. 58, No. 12, 724-731, doi:10.5545/sv-jme.2012.708

[4] Duplakova, D.; Teliskova, M.; Duplak, J.; Torok, J.; Hatala, M.; Steranka, J.; Radchenko, S. (2018). Determination of optimal production process using scheduling and simulation software, International Journal of Simulation Modelling, Vol. 17, No. 4, 609-622, doi:10.2507/ IJSIMM17(4)447

[5] Dima, I. C.; Gabrara, J.; Modrak, V.; Piotr, P.; Popescu, C. (2010). Using the expert systems in the operational management of production, Proceedings of the $11^{\text {th }}$ WSEAS International Conference on Mathematics and Computers in Business and Economics, 307-312

[6] Battaïa, O.; Dolgui, A. (2013). A taxonomy of line balancing problems and their solution approaches, International Journal of Production Economics, Vol. 142, No. 2, 259-277, doi:10.1016/j.ijpe.2012.10.020

[7] Liao, L.-M. (2014). Construction and comparison of multi-model and mixed-model assembly lines balancing problems with bi-objective, Journal of Industrial and Production Engineering, Vol. 31, No. 8, 483-490, doi:10.1080/21681015.2014.992984

[8] Jin, M.; Wu, S. D. (2003). A new heuristic method for mixed model assembly line balancing problem, Computers \& Industrial Engineering, Vol. 44, No. 1, 159-169, doi:10.1016/S0360$\underline{8352(02) 00190-0}$

[9] Chen, W.; Hao, Y. F. (2018). Genetic algorithm-based design and simulation of manufacturing flow shop scheduling, International Journal of Simulation Modelling, Vol. 17, No. 4, 702-711, doi:10.2507/IJSIMM17(4)CO17

[10] Modrak, V.; Soltysova, Z. (2018). Development of operational complexity measure for selection of optimal layout design alternative, International Journal of Production Research, Vol. 56, No. 24, 7280-7295, doi:10.1080/00207543.2018.1456696

[11] Fisel, J.; Arslan, A.; Lanza, G. (2017). Changeability focused planning method for multi model assembly systems in automotive industry, Procedia CIRP, Vol. 63, 515-520, doi:10.1016/ i.procir.2017.03.148

[12] Hachicha, W.; Ammeri, A.; Masmoudi, F.; Chabchoub, H. (2010). A multi-product lot size in make-to-order supply chain using discrete event simulation and response surface methodology, International Journal of Services, Economics and Management, Vol. 2, No. 3-4, 246-266, doi:10.1504/IJSEM.2010.033366

[13] Karimi, B.; Fatemi Ghomi, S. M. T.; Wilson, J. M. (2003). The capacitated lot sizing problem: a review of models and algorithms, Omega, Vol. 31, No. 5, 365-378, doi:10.1016/S03050483(03)00059-8

[14] Jans, R.; Degraeve, Z. (2008). Modeling industrial lot sizing problems: a review, International Journal of Production Research, Vol. 46, No. 6, 1619-1643, doi:10.1080/00207540600902262

[15] Glock, C. H. (2012). Lead time reduction strategies in a single-vendor-single buyer integrated inventory model with lot size-dependent lead times and stochastic demand, International Journal of Production Economics, Vol. 136, No. 1, 37-44, doi:10.1016/j.ijpe.2011.09.007

[16] Silva, C.; Magalhaes, J. M. (2006). Heuristic lot size scheduling on unrelated parallel machines with applications in the textile industry, Computers \& Industrial Engineering, Vol. 50, No. 1-2, 76-89, doi:10.1016/j.cie.2006.01.001

[17] Lauff, V.; Werner, F. (2004). Scheduling with common due date, earliness and tardiness penalties for multi-machine problems: a survey, Mathematical and Computer Modelling, Vol. 40, No. 5-6, 637-655, doi: $10.1016 / \mathrm{j} . \mathrm{mcm} .2003 .05 .019$ 
[18] Semanco, P.; Modrak, V. (2012). A comparison of constructive heuristics with the objective of minimizing makespan in the flow-shop scheduling problem, Acta Polytechnica Hungarica, Vol. 9, No. 5, 177-190

[19] Modrak, V.; Pandian, R. S. (2010). Flow shop scheduling algorithm to minimize completion time for $n$-jobs $m$-machines problem, Tehnicki vjesnik - Technical Gazette, Vol. 17, No. 3, 273-278

[20] Panda, A.; Dyadyura, K.; Valicek, J.; Harnicarova, M.; Zajac, J.; Modrak, V.; Pandova, I.; Vrabel, P.; Novakova-Marcinčinova, E.; Pavelek, Z. (2017). Manufacturing technology of composite materials-principles of modification of polymer composite materials technology based on polytetrafluoroethylene, Materials, Vol. 10, No. 4, Paper 377, 20 pages, doi:10.3390/ $\underline{\operatorname{ma} 10040377}$

[21] Chen, R.-J.; Chen, F.; Chun, T.-G. (2005). Inverse problems of a single machine scheduling to minimize the total completion time, Journal of Shanghai Second Polytechnic University, Vol. 2005, No. 2, 1-7

[22] Xu, L. Z.; Xie, Q. S.; Yuan, Q. N.; Huang, H. S. (2019). An intelligent optimization algorithm for blocking flow-shop scheduling based on differential evolution, International Journal of Simulation Modelling, Vol. 18, No. 4, 678-688, doi:10.2507/IJSIMM18(4)CO16

[23] Modrak, V.; Mandulak, J. (2009). Mapping development of MES functionalities, Proceedings of the $6^{\text {th }}$ International Conference on Informatics in Control, Automation and Robotics, 244-247, doi: $10.5220 / 0002248902440247$

[24] Vieira, A. A. C.; Dias, L. M. S.; Santos, M. Y.; Pereira, G. A. B.; Oliveira, J. A. (2018). Setting an Industry 4.0 research and development agenda for simulation - a literature review, International Journal of Simulation Modelling, Vol. 17, No. 3, 377-390, doi:10.2507/ IJSIMM17(3)429

[25] Yao, J.; Liu, L. (2009). Optimization analysis of supply chain scheduling in mass customization, International Journal of Production Economics, Vol. 117, No. 1, 197-211, doi:10.1016/ j.ijpe.2008.10.008

[26] Al-Zubaidy, S. S.; Mahmoud, M. A.; Khalaf, I. D. (2016). Balancing mixed-model assembly line in electronic industries company, Engineering and Technology Journal, Vol. 34, No. 2, 233-244

[27] Van Zante-de Fokkert, J. I.; de Kok, T. G. (1997). The mixed and multi model line balancing problem: a comparison, European Journal of Operational Research, Vol. 100, No. 3, 399-412, doi:10.1016/S0377-2217(96)00162-2

[28] Modrak, V.; Soltysova, Z.; Modrak, J.; Behunova, A. (2014). Reducing impact of negative complexity on sustainability of mass customization, Sustainability, Vol. 9, No. 11, Paper 2014, 16 pages, doi:10.3390/su9112014

[29] Duray, R.; Ward, P. T.; Milligan, G. W.; Berry, W. L. (2000). Approaches to mass customization: configurations and empirical validation, Journal of Operations Management, Vol. 18, No. 6, 605-625, doi:10.1016/S0272-6963(00)00043-7

[30] Chatzopoulos, C. G. (2014). Flow customizer: an algorithm to design lean-flow production systems for mass customization, International Journal of Industrial Engineering and Management, Vol. 5, No. 4, 179-194

[31] Dallasega, P.; Woschank, M.; Zsifkovits, H.; Tippayawong, K.; Brown, C. A. (2020). Requirement analysis for the design of smart logistics in SMEs, Matt, D.; Modrak, V.; Zsifkovits, H. (Eds.), Industry 4.0 for SMEs, Palgrave Macmillan, 147-162, doi:10.1007/978-3-030-25425$\underline{4} 5$

[32] Genetic Algorithm for Batch Sizing Problem. Online Computing Software, from http://paseka.epizy.com, accessed on 15-02-2018

[33] Alharkan, I. M. (2005). Algorithms for Sequencing and Scheduling, $1^{\text {st }}$ edition, King Saud University, Riyadh

[34] Zhang, Z.; Cheng, W.; Song, L.; Yu, Q. (2009). An ant-based algorithm for balancing assembly lines in a mass customization environment, Proceedings of the 2009 International Workshop on Intelligent Systems and Applications, Vol. 1, 4 pages, doi:10.1109/IWISA.2009.5072706

[35] Bhattacharjee, T. K.; Sahu, S. (1990). Complexity of single model assembly line balancing problems, Engineering Costs and Production Economics, Vol. 18, No. 3, 203-214, doi:10.1016/0167-188X(90)90122-X 